\title{
The Impact of Autocratic, Democratic and Laissez-Faire Leadership Styles on the Success of the Organization: A Study on the Different Popular Restaurants of Mymensingh, Bangladesh
}

\author{
Mohammad Toriqul Islam Jony ${ }^{1}$, Md. Jahangir Alam ${ }^{1}$, Mohammad Rafiqul Amin ${ }^{2}$, and Md. Jahangir \\ Alam $^{3}$ \\ ${ }^{1}$ Dept. of Management, Jatiya Kabi Kazi Nazrul Islam University, Trishal, Mymensingh, Bangladesh; ${ }^{2}$ Dept. of Human \\ Resource Management, Jatiya Kabi Kazi Nazrul Islam University, Trishal, Mymensingh, Bangladesh; and ${ }^{3}$ Dept. of Business \\ Administration, Gono University, Dhaka, Bangladesh. \\ *Correspondence: jony.jkkniu@gmail.com
}

\section{ABSTRACT}

This study aims to show the influence of the three types of leadership style: Autocratic, Democratic and Laissez-Faire on an organization's success and the study was conducted through a field survey of 60 respondents from different popular restaurants of Mymensingh, Bangladesh. The researchers designed and administered a well designed structured questionnaire in a combination which includes both open and close to collect data. After collecting data from the field, the researchers carry out a comprehensive statistical analysis to analyze the research objectives. However; the study finds that the driving factors that have a major impact on the organizational performance are Advice, Decision Making, Involvement, Consultation, and Shared and the democratic leadership style has a strong affirmative impact on the organizational performance. The factors: Leadership barriers, Expression of views, Communication, Stay out of the way, Freedom, Rewards or Punishment, Policies, Refusal to explain and Order and Procedures are not available in the results of the organizations. The study also finds that the factors of autocratic leadership have a significant negative impact on the organizational and the style of laissez-faire management does not affect the organizations outcomes.

Keywords: Organizational performance, Democratic, Leadership style, Factors, and Productivity.

\section{INTRODUCTION:}

For the past couple of decades, leadership has got a lot of awareness and review from researchers. Leadership's impact on organizational outcome is now clearly recognized and accepted in the relevant literature with evidence suggesting that effective leadership improves employee, group and organizational outcomes (Avolioet et al., 2009; Sarrow, 2009). Besides; effective leadership is one of the major fundamental components of an organization's overall strategy to sustain its business, UniversePG I www.universepg.com even with the problems caused by the rapid growth of the economy (Cabeza Erikson, Edwards, and Van Brabant, 2008). In the word of Deng and Gibon (2008) \& Draft and Lane (2005), there are more than 350 definitions for the term 'leadership'. Leader effectiveness refers to the ability to supervise and control subordinates (Enshassi and Burgess, 1991). There is an increasing trend to analyze and test the main feature of a successful leader to achieve high organizational outcomes (Jony et al., 2019). It seems that there is a range of attributes and behaviors that 
differentiate successful leaders from less successful ones.

However, organizational success is dependent on effective leadership (Khan, 2002). In addition to it; leaders are the individual who manages and assumes responsibility for an organization's activity, and the great leaders will set optimistic goals and objectives while guiding the organization's operation through successful procedure toward those goals. Furthermore, great leaders can also influence and motivate their employees by strengthening a positive organizational culture and benefiting liberal employees such as protection of human services, pay for workers, leave advantage, etc. Apart from it; the leader's key role is to create the organizational and human resources needed to build an individual's capacity to support effective governance.

Nowadays, organizations need a suitable leadership style that responds to the dynamic change in business environments and is more customers focused. Organizational leaders face prominent challenges in adapting to a new leadership model and paradigms while leading employees from a variety of backgrounds. Leaders should not be haphazard or inconsistent in their leadership style. In addition, the long-standing effectiveness of leadership development programs includes an organizational culture that views the development of future leaders as a priority of longterm strategy (Block and Manning, 2007). A large number of attentions have been given to leadership style; since subordinates like to work more efficiently and productively when their managers adopt a specific leadership style (Mullins, 1998).

Leadership style is, therefore, the most important issue in the leadership process because managers develop leadership styles through their education, training and experience (Hersey, Blanchard \& Johnson, 2001). This caused leadership to be the greatest social phenomena studied and is critical for the effectiveness of business and social organizations functions. Many managers follow only one leadership style and management style has a big impact on the operation of the organization. Effective management style will increase productivity, inspire, enhance morale, encourage workers and make a positive contribution to UniversePG I www.universepg.com the company and so on (Judge and Piccolo, 2004). Leadership can initiate ways to the greater efficiency and performance but the level of success depends on the style of leadership and the organizational climate of employee usability. Organization has to select a suitable leadership style for being successful in the current competitive market and there are a lot of restaurants in Mymensingh, Bangladesh; many of them have failed in this business and only a few have succeeded in this business, as their growth rate is very good. Our study is to identify the influence of the three leadership style: Autocratic, Democratic and Laissez-faire leadership on the output and identify which leadership style influences the most on the success of this restaurant.

Autocratic Leadership Style: A type of leadership characterized by individual control over the actions of all group members and little input. Usually, autocratic leaders make choice based on their beliefs and judgments and seldom consider follower's advice which requires a group's absolute \& authoritarian control (Cherry, 2019). These types of leaders want their subordinates to functions as they command ( $\mathrm{Al}$ Khajeh, 2018). Autocratic leadership may be useful in emergency situations where there is a homogeneous workforce, where the leader is wise, fair and has a good understanding of the followers (Armstrong, 2012). Nevertheless, in some cases, it is appropriate to act autocratically. It is critical when the company is facing a crisis or an urgent problem requiring an immediate response (Bhargavi \& Yaseen, 2016).

Democratic Leadership Style: Democratic leadership, also known as participatory or collective leadership; a kind of style in where members of the group are more active in the process of making decision (Cherry, 2019). In a democratic system, decision making is not centralized and the quality is appreciated and rewarded (Puni et al., 2014). Contrarily, it is suggested that, depending on the contribution made by the employees or subordinates, there is potential for poor decisions to be made by subordinates (Nwochoka \& Iheriohanma, 2015). This can be said to have a negative impact on the organization and may also give rise to employee turnover intention. Democratic leadership sounds good 
in theory but is often trapped in its sluggish decisionmaking process and the outcomes that might seem possible would always take a lot of time and effort (Nwochoka \& Iheriohanma, 2015) and even though subordinates are encouraged to share their ideas; it can lead to better ideas and innovative solution to problems (Sadia \& Aman, 2018).

Laissez Faire Leadership Style: Laissez-faire leadership is a style of leadership in which leaders are hands in hands and enable members of the group to make decisions (Cherry, 2019). Moreover; the style in which the leader does not believe in his own supervisory capacity and the leader has no clear goals as to how they can work, does not help the group to make decisions and therefore; it leaves too much burden for subordinates, (Bass \& Bernard, 1985). This leadership style cannot be functional in the banking sector or non-governmental organizations which allow both the leader and subordinates to contribute to the decision-making process and complete tasks to ensure the organization's performance. This is described as the style of leadership where leaders refuse to make decisions. However, laissez-faire leaders were argued not to invest in the advancement of workers because they believe that employees can take care of themselves (Puni et al., 2014) which results in unhappiness, unproductively and inefficiency (Deluga, 1992).

Organizational performance: Organizational quality in business literature is a dynamic and multidimensional phenomenon. Its success consists of an organization's outcomes or an organization's actual output that can be calculated against expected outputs, objectives and targets. Organizational performance is more of an organization's survival and profitability. Its measurement in both the service and manufacturing sector is critical (Atkinson \& Brown, 2001). An organization's success can be evaluated subjectively and objectively. Real figures are taken into account in objective measures where the view of the entity in the community is clutched into consideration as in subjective measures (Johannessen et al., 1999).

The Style of Leadership and organizational Success: Leadership is the way how a manager decides to behave with his or her employees or UniversePG I www.universepg.com subordinates and the way in which they exercise the leadership role (Mullins, 2000). Besides, effective leadership provides an adequate response to time, culture, desires and needs environmental factors and their harmonization to ensure that these factors operate smoothly to maximize the organization's profit and growth (Anuku \& Achienu, 2001). Anyway, the success or failure of an organization, nations and other social structures was largely attributable to their leadership style (Oladipo et al., 2013).

Not only does an outstanding leader inspire the potential of subordinates in order to improve performance but they also satisfy their requirements to attain organizational goals. There are indicators that there is a relation between the style of leadership and performance of the organization. The dynamic market today demands an innovative approach to competition, differentiated product/service, reduced margins and creativity that replaces existing skills (Santora et al., 1999).

Nevertheless, the impact of styles of management on the output of the company and also found a strong relationship between styled management and organizational success. Leadership style has an influential relationship with organizational performance, and different leadership styles may have a positive correlation or negative correlation with organizational performance depending on the variables used by researchers (Wang et al., 2010). McGrath \& MacMillan (2000) conclude that the style of leadership and organizational output are strongly related. Effective leadership style is seen as a powerful source of sustained competitive advantage and development management (Al Khajeh, 2018).

Leadership style helps the company meet its current goals more effectively by connecting job outcomes with valued opportunities and ensuring that staff has the tools to do the job. Sun (2002) compared leadership style with leadership performance in schools and businesses and found that leadership style in both schools and businesses had a significantly positive correlation with organizational performance. According to Kotter (1995), without management, the risk of errors happening rises and the prospects for success becomes more and more decreasing. In this 
way, leadership, along with incentives and opportunities, facilitates the motivation of people to achieve common goals and plays a key role in the processes of creating, distributing and improving organizational culture (Senge, 1990).

\section{Literature Review:}

Ojokuku et al. (2012) explored a study on the effect of leadership style on organizational performance among the Nigerian Bank in Nigeria. The findings showed that the relationship between success and leadership style was both affirmative and unproductive in some cases. There was a performance variance of 23 percent found to jointly predict leadership-styles of organizational efficiency. This study concluded that constructive and inclusive leadership styles have positive effects on results and adherents.

Dalluay \& Jalagat (2016) conducted a study in Cavite, Philippines on the impacts of leadership style effectiveness of managers and department heads on job satisfaction and productivity of workers in selected small businesses. The result concluded that, although there is room for improvement, organizations must continually make the most of the leadership style that increases employee productivity and a reasonable level of employee work.

Nasir et al. (2014) conducted research on Leadership Styles Relationship and IPTA Educational Leadership and Organizational Success in Malaysia's Klang Valley Area. The study used methods of correlation for evaluating the relationship between styles of leadership and performance of organizations. The findings concluded that styles of leadership have had a significant impact on employee engagement.

Ukaidi (2016) investigated a study on the effect of styles of leadership on organizational performance to examine two Nigerian University's leadership styles. It was noted that the style of democratic leadership had a positive impact on the organization's results compared to other forms of leadership: autocratic \& Laissez faire style of leadership.

Mohammad, Chowdhury \& Sanju (2017) their research was aimed at defining the correct leadership in Bangladesh's banking industry. They found that the administrative style of leadership is mostly practiced in the banking sector relative to other leadership styles.

In their study, Basit, Sebastian \& Hassan (2017) tried to pinpoint the numerous leadership style factors that mostly influence on employee performance in Malaysian private company. They also noticed that the style of democratic leadership has a greater influence on the organization's quality performance.

Khan \& Adnan (2014) their study aimed to focus the organization's performance on the appropriate leadership style. They identified that the transformation leadership has a strong affirmative influence on the employee's performance, resulting in greater for the business.

Akther (2015) conducted a study to investigate manager's leadership styles during mergers in Bangladesh's hospitality industry. Ten managers were stripped from the Dhaka \& Chittagong division to participate in this study, showing that their behavior is marked by tension, anxiety, cultural shock and job insecurity during mergers and acquisitions.

The above literature suggests that many studies were explored in the area of leadership, but there is a noticeable gap that only a few of them are conducted in Bangladesh and none of them have demonstrated the effect of three leadership styles: Autocratic, Democratic and Laissez Faire leadership on the organizational success among the successful Organizations.

\section{Research Questions:}

This study provides us with the answer of the following questions;

I. What are the effects of the three style of leadership: autocratic, democratic and laissez faire leadership on the success of the organization?

II. Which of the leadership styles are being adopted in the successful restaurants of Mymensingh? 


\section{Significance of the study:}

To be effective, a leader has to determine which of the leadership styles are appropriate in which situations. If an organization can better identify the style of leadership on the basis of the changing nature of time or based on a situations. It will certainly manage its employee effectively and sustain eventually profitably. Throughout the conducting of this study; the organizations will successfully identify a suitable leadership style which will respond in the dynamic change of the business environment.

\section{Objectives of the study:}

The main aim of this study is to describe and identify the nature of three styles of leadership and its impact on the success among the different popular restaurants of Mymensingh, Bangladesh.
The specific objectives are:

i. To explore about the three leadership styles;

ii. To identify the leadership styles followed among the popular restaurants of Mymensingh;

iii. To identify the relations of three leadership style on the success of the different popular restaurants of Mymensingh;

\section{Theoretical framework of the study:}

The theoretical framework of the study is to explore the impacts of the leadership styles of managers on the organizational performance of staff working various popular Mymensingh restaurants. The leadership style of the manager is an independent variable and a dependent variable is organizational performance. The relation between styles of leadership was designed to be positive and has a good influence on the success of the company.

\section{Autocratic Leadership Style \\ 1. Assessment \\ 2. Policies \\ 3. Orders and procedures \\ 4. Rewards or Punishment \\ 5. Refuse to explain}

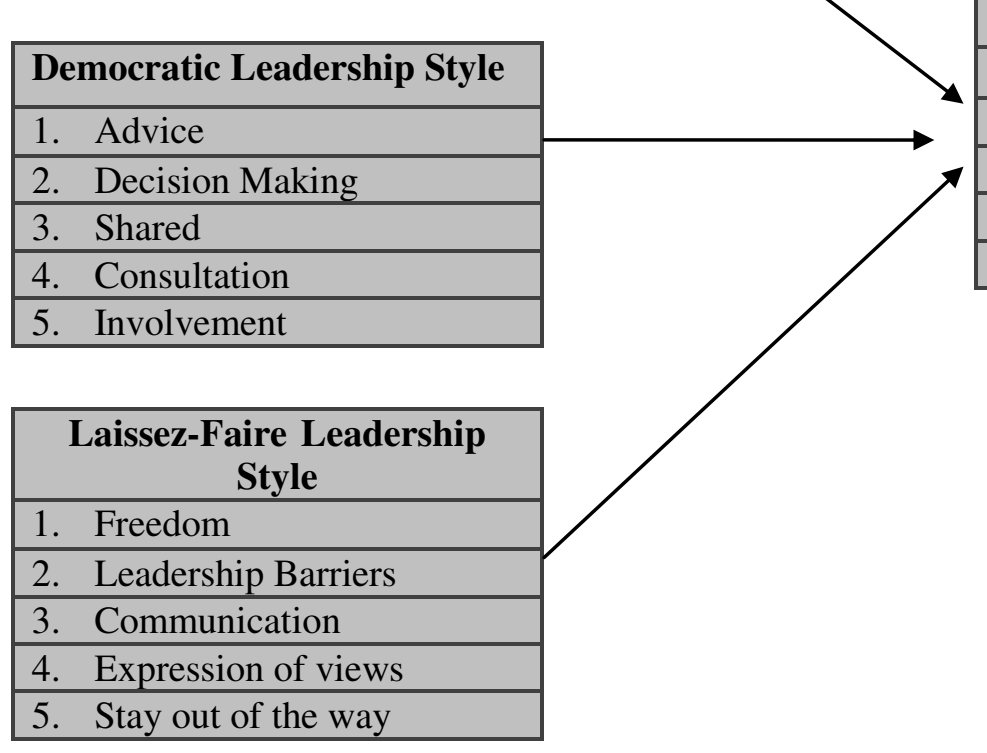

\section{Organizational Performance}

1. Profitability

2. Number of Customers

3. Customer Satisfaction

4. Employee Satisfaction

5. Level of Learning and Knowledge

Fig 1: Theoretical framework of the study. 
Hypothesis of the Study: This study draws the following hypothesis to test -

1. H1: The style of autocratic leadership has a positive impact on organizations success.

2. H2: The style of Democratic Leadership has a positive impact on organizations success.

3. H3: The leadership style of Laissez Faire has a positive impact on the organizations' success.

\section{MATERIAL AND METHODS:}

Data Collection, Tools and respondents: This analysis used both primary and secondary data. The data was collected from the randomly selected 60 employees of various popular Mymensingh district restaurants through a well-structured questionnaire. The five point Likert-type scale where 5= Excellent and $1=$ Very Poor was also used in this study.

This study used two iterations of the questionnaire. The first part is based on three leadership styles with 15 questionnaires (Source: Basit, Sebastian \& Hassan, 2017); the second part is organizational performance based on 7 questionnaires (Kulkarni, 2016).

Pre-Test and Pilot Testing: The study pre-tested the questionnaire to see if the actual survey requires changes. In the pre-testing (pilot survey) session, 10 people with the same characteristics as respondents were selected. The pilot survey found some important questionnaire correction areas such as core and functional meaning comprehension, and some potential areas of confusion or ambiguity. The questionnaire has been modified based on pre-test results and unnecessary items and confusing words have been removed.

Data analysis tools: The responses of the participants were put into SPSS version 16.0 software to arrive at the intended analysis and several sets of statistical analysis were performed to interpret the data. Descriptive statistics were used to demonstrate the existence of the three styles of leadership on employee performance in organizations and analysis of regression was also used to analyze factors relating to the dependence of managers' leadership styles on the output of the company.

Reliability of data: The initial reliability of the items was evaluated by calculating the alpha of the Cronbach. The following thumb rules were provided by George and Mallery (2003): " >0.9 - Excellent, $>0.8$ - Good, $>0.7$ - Acceptable, $>0.6$ - Controversial, $>0.5$-Poor, and < 0.5 -Improper." The alpha value of Cronbach for all variables was 0.753 (Table 1). Thus, as the alpha of the Cronbach was much higher than the 0.6 , the constructs were considered to be reasonably accurate.

Table 1: Reliability Statistics.

\begin{tabular}{|c|c|}
\hline \multicolumn{2}{|c|}{ Reliability Statistics } \\
\hline Cronbach's Alpha & No. of Items \\
\hline 0.753 & 20 \\
\hline
\end{tabular}

Demographic information of the respondents: The table below (Table 2) shows the composition of the respondents:

Table 2: Profiles of the respondents.

\begin{tabular}{|l|l|l|l|}
\hline Particulars & Percentage & Particulars & Percentage \\
\hline AGE & \multicolumn{2}{l|}{} \\
\hline $20-30$ & 43.8 & JOB NATURE & 32.3 \\
\hline $30-40$ & 34.7 & Temporary & 67.7 \\
\hline $40-50$ & 17.3 & Permanent & 100.0 \\
\hline $50-60$ & 4.2 & Total & \multicolumn{2}{|l|}{} \\
\hline Total & 100.0 & EXPERIENCE & 36.0 \\
\hline SALARY & & Below 3 Years & 50.7 \\
\hline Below 15000 & 49.3 & 3-6 Years & 13.3 \\
\hline 10000-20000 & 43.7 & 6-9 Years & 100.0 \\
\hline
\end{tabular}




\begin{tabular}{|l|c|l|c|}
\hline 20000-Above & 07.0 & MARITAL STATUS \\
\hline EDUCATION & & Unmarried & 43.3 \\
\hline Under graduate & 92.0 & Married & 53.1 \\
\hline Graduate & 8.0 & Divorced & 3.6 \\
\hline Total & 100.0 & Total & 100.0 \\
\hline
\end{tabular}

Table 2 above shows that most respondents are 20-40 years of age (43.8 percent), most of them earn a salary below 15,000 (49.3 percent) per month, nearly all of them (92 percent) have not completed graduation and are in permanent employment (67.7 percent). The table also reveals that most respondents $(50.7 \%)$ have 3-6 years of work experience and most of them are married $(53.1 \%)$.

\section{ANALYSIS AND FINDINGS:}

Respondents' opinion regarding the factors of three leadership styles and success of the company. Table 3 below shows the descriptive statistics based on the opinion of the respondents for each of the factors of three leadership styles and organizational performance.

Table 3: The respondents' opinion regarding the factors of three leadership styles and success of the company.

\begin{tabular}{|l|l|l|}
\hline Particulars & Mean & Std. Deviation \\
\hline Assessment & 3.0167 & 0.67627 \\
\hline Policies & 2.8833 & 0.66617 \\
\hline Orders and procedures & 2.9500 & 0.67460 \\
\hline Rewards or Punishment & 2.8000 & 0.65871 \\
\hline Refuse to explain & 2.9167 & 0.71997 \\
\hline Advice & 3.7500 & 0.50840 \\
\hline Decision Making & 3.7000 & 0.59089 \\
\hline Shared & 3.6167 & 0.58488 \\
\hline Consultation & 3.6333 & 0.63691 \\
\hline Involvement & 3.6500 & 0.57711 \\
\hline Freedom & 2.7333 & 0.57833 \\
\hline Leadership Barriers & 2.4167 & 0.56122 \\
\hline Communication & 2.5167 & 0.62414 \\
\hline Expression of views & 2.4500 & 0.56524 \\
\hline Stay out of the way & 2.5333 & 0.56648 \\
\hline OP & 3.5733 & 0.48638 \\
\hline
\end{tabular}

Scale: 5=Excellent, 1=Very Poor

The Table 3 indicates that the highest mean value for the factors Advice, Decision Making, Involvement, Consultation and Shared are 3.75, 3.70, 3.65, 3.63 and 3.62 respectively. It indicates that as per the opinion the respondents these factors are sufficiently available in their organizations, conversely, the opinion of the respondents also indicates that, the factors Leadership barriers (2.41), Expression of views (2.45), Communication (2.51), Stay out of the way (2.53), Freedom (2.73), Rewards or Punishment (2.80), Policies (2.88), Refusal to explain (2.91) and Order and Procedures (2.95) are not satisfactory in their organizations. The level of organizational performance according to the response of the respondents shows that it is 3.57 on the scale of 5.00 .

Leadership Style's Effect on Organizational Success: This study used the multiple regression analysis to show whether the factors of three leadership styles have any influence on the organizational outcomes or employee performance. The output of the analysis and the interpretation are in the following Table 4. 
Table 4: Leadership Style's Effect on Organizational Success.

\begin{tabular}{|l|l|l|l|l|l|}
\hline Leadership Styles & \multicolumn{1}{|c|}{ B } & \multicolumn{1}{c|}{ Std. Error } & \multicolumn{1}{c|}{ Beta } & \multicolumn{1}{c|}{ Sig. } \\
\hline (Constant) & 0.908 & 0.629 & & 1.444 & 0.154 \\
\hline ALS & -0.044 & 0.117 & -0.040 & -0.374 & 0.710 \\
\hline DLS & 0.727 & 0.128 & 0.610 & 5.699 & 0.000 \\
\hline LFLS & 0.049 & 0.149 & 0.035 & 0.328 & 0.744 \\
\hline \multicolumn{7}{|}{$\begin{array}{r}\text { R }=0.609 \text { and R }{ }^{2}=0.371 \\
\text { a. Dependent Variable: OP }\end{array}$} \\
\hline
\end{tabular}

The above table (Table 4) shows the value of the coefficients of the regression model. It shows that the democratic leadership style (5.699) has a major productive influence on the organization outcome whereas the autocratic leadership style (-0.374) shows a negative influence on the outcomes or performance of the employees and the laissez-faire leadership style (0.328) has no prime effect on the success of the restaurants because its $\mathrm{T}$ value is less than the threshold (1.96).

\section{DISCUSSION:}

The results of the study indicate that democratic leadership has a strong positive influence on the success of the organizations. Through adopting a democratic approach, employee satisfaction and organizational efficiency would increase. To some degree, the power of employees of democratic leadership has the discretion to do work that leads to better results which means the hypotheses 1 is accepted.

The findings also advocate that autocratic leadership style has a major obstructive effect on the performance of employees. This suggests that by implementing an autocratic policy, workers' productivity would not improve. H2: Rejected

Laissez-Faire Leadership does not have any major impact on the success of restaurants. This strategy is ideal when workers have a good understanding of their roles and strong analytical skills, as well as when managers have a high degree of staff trust and do not blame each other for mistakes in any case. H3: Rejected

\section{CONCLUSION:}

The results of the study revealed that the democratic style of leadership has a strong pragmatic effect on organizational performance which supports the findings of Ukaidi, 2016; Basit, Sebastian \& Hassan, 2017. It suggests that employee productivity \& organizational performance will improve by implementing a democratic approach. Restaurant owners are encouraged to embrace democratic leadership and participation of employees in the process of decision-making as it is confirmed that employee performance is the best under this leadership style. Whereas; the style of autocratic leadership has a major obstructive impact on employee performance. This means the productivity of workers would not increase by adopting an autocratic strategy. In addition to it; employees who are now becoming more knowledgeable, independent and competent can no longer accept autocratic leadership style. On the other hand; Laissez Faire Leadership has no major impact on the restaurants ' success. This technique is suited when employees understand their responsibilities well and have strong analytical skills as well as leaders have a high degree of trust in staffs and they do not blame each other for errors in any situation.

\section{Implications of the Study:}

The results of this study will provide new insight to the researchers; as only a few research works is being conducted in this field. The leadership style of democratic has more influence than laissez-faire leadership and autocratic models in terms of employee performance. It will allow companies to take 
appropriate leadership and effectively manage a company with the influences of leadership styles.

\section{Suggestion for further research:}

Much of the research work in this field in Bangladesh has not been done, so it will certainly create new opportunities for future researchers.

- The sample size should be greater than the present study with an aim to achieve the maximum reliability of the test.

- The study area should be expanded.

- The data collection method should be more than one.

\section{ACKNOWLEDGEMENT:}

Many thanks to the co-author for their cordial support and assistance in writing and analysis which helps to conduct this study successfully.

\section{CONFLICTS OF INTEREST:}

The authors declare that they have no competing interests with respect to the research.

\section{REFERENCS:}

1) Ababneh, R. I. (2016). Successful leadership components: A qualitative approach. In WEI International Academic Conference, March, pp. 7-9.

2) Akparep, J. Y., Jengre, E., \& Mogre, A. A. (2019). The Influence of Leadership Style on Organizational Performance at Tuma Kavi Development Association, Tamale, Northern Region of Ghana. Open Journal of Leadership, 8(1), 1-22. https://doi.org/10.4236/oj1.2019.81001

3) Akther, F. (2015). Leadership Style of Managers during Mergers in the Hospitality Industry: A study on Bangladesh. Leadership, 8(02), 29-33.

4) Al Khajeh, E. H. (2018). Impact of leadership styles on organizational performance, Vol. 2018(2018), 1-10. https://doi.org/10.5171/2018.687849

5) Armstrong, M. (2012). Armstrong's handbook of management and leadership: developing effective people skills for better leadership and management. Kogan Page Publishers.

6) Atkinson, H., \& Brander Brown, J. (2001). Rethinking performance measures: assessing progress in UK hotels. International Journal of Contemporary Hospitality Management, 13(3), 128-136. https://doi.org/10.1108/09596110110388918

7) Avolio, B. J., Walumbwa, F. O., \& Weber, T. J. (2009). Leadership: Current theories, resea$\mathrm{rch}$, and future directions. Annual review of psychology, 60, 421-449.

8) Basit, A., Sebastian, V., \& Hassan, Z. (2017). Impact of leadership style on employee performance (A Case study on a private organization in Malaysia). International $J$. of Accounting \& Business Management, 5(2), 2289-4519.

https://doi.org/24924/ijabm/2017.11/v5.iss2/112. $\underline{130}$

9) Bass, B. M., \& Bass Bernard, M. (1985). Leadership and performance beyond expectations, 25 (3), 481-484.

10) Bhargavi, S., \& Yaseen, A. (2016). Leadership styles and organizational performance. Strat Manage Q, 4(1), 87-117.

11) Cabeza-Erikson, I., Edwards, K., \& Brabant, T. V. (2008). Development of leadership capacities as a strategic factor for sustainability, Karlskrona, Sweden, 1-91. http://www.diva-portal.org/smash/get/diva2: 833080/FULLTEXT01

12) Cherry, K. (2019). Autocratic Leadership. Retrieved from https://www.verywellmind. com/what-is-autocratic-leadership-2795314

13) Daft, R. L., \& Lane, P. G. (2005). The leadership experience $\left(3^{\text {rd }}\right)$. Mason, Ohio: Thomson South-Western.

14) Dalluay, V. S., \& Jalagat, R. C. (2016). Impacts of Leadership Style Effectiveness of Managers and Dept. Heads to Employees' Job Satisfaction and Performance on Selected Small-Scale Businesses in Cavite, Philippines. International $J$. of Recent Advances in Organizational Behaviour \& Decision Sciences, 2(2), 734-751. 
15) Deng, L., \& Gibson, P. (2008). A qualitative evaluation on the role of cultural intelligence in cross-cultural leadership effectiveness. International journal of leadership studies, 3(2), 181-197.

16) Enshassi, A., \& Burgess, R. (1991). Managerial effectiveness and the style of management in the Middle East: An empirical analysis. Construction Management and Economics, 9 (1), 79-92. https://doi.org/10.1080/01446199100000008

17) Hersey, P., Blanchard, K. H., \& Johnson, D. E. (2007). Management of organizational behavior (Vol. 9). Upper Saddle River, NJ: Prentice hall.

18) Johannessen, J. A., Olaisen, J., Johannessen, J. A., \& Olsen, B. (1999). Managing and organizing innovation in the knowledge economy. European J. of innovation management, 2(3), 116-128.

19) Jony MTI, Alam MJ, and Rana MS. (2019). Customers' Satisfaction of Service Quality: A Study on the Customers of DBBL at Different Areas of Mymensingh District. Can. J. Bus. Inf. Stud., 1(5), 10-16. https://doi.org/10.3\%204104/cjbis.019.01016

20) Judge, T. A., \& Piccolo, R. F. (2004). Transformational and transactional leadership: a meta-analytic test of their relative validity. Journal of applied psychology, 89(5), 755.

21) Khan, S. (2002). Personal administration with special reference to Pakistan.

22) Khan, A. Z., \& Adnan, N. (2014). Impact of leadership styles on organizational performance. International J. of Management Sciences, 2(11), 501-515. https://ideas.repec.org/a/rss/jnljms/v2i11p2.html

23) Kotter, J. P. (1995). Leading change: Why transformation efforts fail.

24) Kulkarni, C. (2016). 7 ways to measure success. Retrieved from -

https://www.inc.com/chirag-kulkarni/7-ways-tomeasure-true-suc\%20cess.html

25) McGrath, R. G., \& MacMillan, I. C. (2000). The entrepreneurial mindset: Strategies for continuously creating opportunity in an age of uncertainty (Vol. 284). Harvard Business Press.

26) Mohammad, I., Chowdhury, S. R., \& Sanju, N. L. (2017). Leadership Styles Followed in Banking Industry of Bangladesh: A Case Study on Some Selected Banks and Financial Institutions. American J. of Theoretical and Applied Business, 3(3), 36.

https://doi.org/10.11648/j.ajtab.20170303.11

27) Mullins, L. J. (1998). Managing people in the hospitality industry. Addison Wesley Longman Higher Education.

28) Nasir, H. M., Nordin, R., Seman, S. A. A., \& Rahmat, A. (2014). The relationship of leadership styles and organizational performance among IPTA academic leaders in Klang Valley area, Malaysia. Business and Entrepreneurship Journal, 3(2), 45-65.

29) Nwokocha, I., \& Iheriohanma, E. B. J. (2015). Nexus between leadership styles, employee retention and performance in organizations in Nigeria. European Scientific Journal, 11(13), 185-209.

http://eujournal.org/index.php/esj/article/view/5 $\underline{645}$

30) Ojokuku, R. M., Odetayo, T. A., \& Sajuyigbe, A. S. (2012). Impact of leadership style on organizational performance: a case study of Nigerian banks. American Journal of Business and Management, 1(4), 202-207.

31) Oladipo, K. S., Jamilah, O., Abudul Daud, S., Jeffrey, L. D., \& Salami, D. K. (2013). Review of leadership theories and organizational performances. International Business Management, 7(1), 50-54. https://doi.org/10.36478/ibm.2013.50.54

32) Puni, A., Ofei, S. B., \& Okoe, A. (2014). The effect of leadership styles on firm performance in Ghana. International J. of Marketing Studies, 6(1), 177.

33) Sadia, A., \& Aman, A. (2018). Transformational Leadership and Organizational Performance; the mediating Role of organizational Innovation. SEISENSE Journal of Management, 1, 59-75. https://doi.org/10.33215/sjom.v1i3.28 
34) Santora, J. C., Seaton, W., \& Sarros, J. C. (1999). Changing times: Entrepreneurial leadership in a community-based nonprofit organization. J. of Leadership Studies, 6(3-4), 101-109.

https://doi.org/10.1177/107179199900600308

35) Sarros, J. C. (2009). Contemporary perspectives on leadership: Focus and meaning for ambiguous times. Tilde University Press.

36) Senge, P. (1990). The fifth discipline: The art and practice of the learning organization. New York: Currency Doubleday. Senge The Fifth Discipline: The Art and Practice of the Learning Organization.

37) Sternberg, R. J., Cianciolo, A. T., \& Antonakis, J. (Eds.). (2004). The nature of leadership. Sage Publications.

https://psycnet.apa.org/record/2006-10875-000
38) Sun, R. Y. (2002). The relationship among the leadership style, organizational culture and organizational effectiveness based on competing value framework: An empirical study for the institute of technology in Taiwan. Unpublished doctoral dissertation, National Taipei University, Taipei, Taiwan.

39) Ukaidi, C. U. (2016). The influence of leadership styles on organizational performance in Nigeria. Global Journal of Human Resource Management, 4(4), 25-34.

40) Wang, F. J., Chich-Jen, S., \& Mei-Ling, T. (2010). Effect of leadership style on organizational performance as viewed from human resource management strategy. African Journal of Business Management, 4(18), 3924-3936.

https://academicjournals.org/journal/AJBM/artic le-full-text-pdf/0B1696A16102

Citation: Jony MTI, Alam MJ, Amin MR, and Alam MJ. (2019). The impact of autocratic, democratic and laissez-faire leadership styles on the success of the organization: a study on the different popular restaurants of Mymensingh, Bangladesh, Can. J. Bus. Inf. Stud., 1(6), 28-38. https://doi.org/10.34104/cjbis.019.028038 (c) † 